\title{
INFLUÊNCIA DA GEOMETRIA DA PLATAFORMA NA DETERMINAÇÃO DE CHUMBO EM ZIDOVUDINA (AZT) POR ET AAS
}

Fátima R. Moreira*, Josino C. Moreira e Fatima Pivetta

Centro de Estudos da Saúde do Trabalhador e Ecologia Humana, Escola Nacional de Saúde Pública, Fundação Oswaldo Cruz, Av. Leopoldo Bulhões, 1480, 21041-210 Rio de Janeiro - RJ

Leonardo Coutada

Instituto de Tecnologia em Fármacos (Far-Manguinhos), Fundação Oswaldo Cruz, Rua Sizenando Nabuco, 100, $21041-250$

Rio de Janeiro - RJ

Recebido em 21/2/01; aceito em 3/10/01

\begin{abstract}
INFLUENCE OF THE PLATFORM GEOMETRY ON LEAD DETERMINATION IN ZIDOVUDINE (AZT) BY ET AAS. The aim of this work was to compare the performances of the L'vov and integrated platforms in order to overcome the interferences found on lead determination in zidovudine by ET AAS. Pyrolysis and atomization temperatures found with integrated platform were 700 and $1400^{\circ} \mathrm{C}$, respectively. The characteristic masses were $12.7 \pm 1.2 \mathrm{pg}$ with integrated platform and $11.1 \pm 1.3 \mathrm{pg}$ with grooved platform. The ratio between the slopes of zidovudine and aqueous curves shows a decrease in the interferences when the L'vov platform is used $\left(\mathrm{b}_{\mathrm{AZI}} / \mathrm{b}_{\mathrm{aq}}=0.97 \pm 0.10\right)$ and the detection limit found was $0.03 \mu \mathrm{g} \cdot \mathrm{g}^{-1}$. That ratio was $0.85 \pm 0.07$ with the integrated platform.
\end{abstract}

Keywords: lead; platform geometry; interferences.

\section{INTRODUÇÃO}

Nos últimos anos, vem crescendo o interesse sobre a acumulação e os efeitos tóxicos de metais traço, resultantes de exposição ocupacional ou ambiental no organismo humano ${ }^{1}$. Os distúrbios causados por estes elementos, induzidos por situações especiais de doença, também têm despertado a curiosidade dos pesquisadores, já que os efeitos de uma exposição por ingestão de medicamentos podem ser agravados pela debilidade dos organismos ${ }^{2-4}$.

Dentre os metais, o chumbo é um dos contaminantes ambientais mais comuns, possuindo efeitos extremamente tóxicos e nenhuma função fisiológica já identificada no organismo ${ }^{5}$. Este metal afeta praticamente todos os órgãos e sistemas do corpo humano, causando danos crônicos, tais como hematológicos e neurológicos, em níveis antes considerados seguros ${ }^{6}$. O chumbo é um metal cumulativo e uma de suas principais vias de absorção é o trato gastrointestinal, onde é absorvido, em média, $10 \%$ do chumbo ingerido ${ }^{7}$. A absorção do chumbo é influenciada pelas variações individuais fisiológicas e patológicas, entre outras. A deficiência de nutrientes como cálcio, ferro, fósforo e proteínas aumentam a absorção do chumbo ${ }^{7-10}$.

A ingestão de contaminantes através de medicamentos, sob condição de fragilidade do organismo, e as evidências de toxicidade cada vez mais claras, mostram a importância da manutenção dos níveis de elementos tóxicos, como os metais, em matérias primas e produtos acabados próximos de zero. Este controle é baseado nas normas e padrões de qualidade das farmacopéias que, embora revisadas para a maioria dos parâmetros necessários à garantia da qualidade dos medicamentos, não têm acompanhado a evolução dos estudos sobre toxicidade dos metais e o desenvolvimento das técnicas analíticas. Muitas vezes, as concentrações encontradas não são detectáveis pelos métodos recomendados pelas farmacopéias, que têm como limite máximo permitido de $\mathrm{Pb}$ em matérias primas para a

*e-mail: fmoreira@ensp.fiocruz.br produção de medicamentos, a faixa 10 - $20 \mu \mathrm{g} \mathrm{g}^{-1}$. Além disso, existe uma grande variação na concentração deste metal entre as diversas matérias primas de diferentes procedências, que pode resultar em exposição crônica devido à necessidade de uso prolongado dos mesmos, como no caso da AIDS e das doenças crônicas ${ }^{11}$.

A zidovudina (AZT) é um agente antiviral e amplamente utilizada no tratamento da síndrome da imunodeficiência adquirida (AIDS) ${ }^{12}$ por ser altamente eficaz no bloqueio da replicação viral ${ }^{13-14}$ e na melhora da função imunológica dos pacientes com doença pelo vírus da imunodeficiência humana (HIV) ${ }^{14}$. Considerando a exposição crônica de um organismo debilitado, vulnerável a doenças oportunistas, mesmo em baixos níveis de concentração, e os efeitos cumulativos e neurotóxicos do $\mathrm{Pb}$, o controle deste contaminante com métodos capazes de detectar teores mínimos é imprescindível tanto para o controle de qualidade da produção como para as ações de vigilância sanitária, uma questão de saúde pública, já que envolve consumidores de medicamentos.

O desenvolvimento instrumental tem contribuído para a identificação das formas químicas tóxicas e a elucidação dos mecanismos de ação dos metais no organismo ${ }^{15}$. Técnicas analíticas específicas e sensíveis para o controle destes contaminantes são fundamentais para a prevenção da contaminação dos usuários e possíveis interferências nos processos de produção ${ }^{11}$.

Entre as técnicas instrumentais, a espectrometria de absorção atômica (AAS) é amplamente utilizada na determinação de metais traço nas mais variadas matrizes, por ser específica, altamente sensível, rápida, confiável e possibilitar a análise direta de amostras ${ }^{7}$. Estas características são necessárias para atender à grande demanda do setor de produção, que precisa de respostas rápidas por parte do laboratório de controle da qualidade ${ }^{11}$.

O conceito STPF ("Stabilized Temperature Platform Furnace" Forno Plataforma com Temperatura Estabilizada) é um conjunto de condições que devem ser usadas ao mesmo tempo, para garantir determinações livres de interferência no forno de grafite. Entre estas, encontra-se o uso de plataforma, necessária para atrasar a atomização do 
analito o maior tempo possível, até que as paredes do tubo e a atmosfera gasosa alcancem o equilíbrio térmico ${ }^{16,17}$. Atualmente, existem dois tipos de plataformas comercialmente disponíveis, a plataforma de L'vov e o tubo com plataforma integrada. Segundo Lajunen ${ }^{16}$, o aquecimento excepcionalmente rápido da plataforma de menor massa, como é o caso da integrada, leva à maior eficiência de atomização e a temperaturas de atomização mais baixas, proporcionando maior tempo de vida para o tubo de grafite e menor tempo de análise ${ }^{16,17}$.

O objetivo deste trabalho foi desenvolver um procedimento rápido de rotina, sem uso de modificador, para a determinação de chumbo em zidovudina por AAS no forno de grafite, com um pré-tratamento mínimo da amostra. Plataformas com diferentes geometrias (L'vov e integrada) e variações na temperatura de atomização foram estudadas na tentativa de obter melhores resultados, uma vez que o uso da plataforma integrada deveria reduzir as interferências observadas com a de $\mathrm{L}^{\prime} \mathrm{vov}^{17}$.

\section{PARTE EXPERIMENTAL}

\section{Instrumental}

Um espectrômetro de absorção atômica Zeeman 5100 com forno de grafite HGA - 600 e amostrador automático AS - 60, todos Perkin-Elmer, foi utilizado neste trabalho. O comprimento de onda da lâmpada de catodo oco (Perkin-Elmer) de chumbo foi de 283,3 nm e a largura da fenda foi de $0,7 \mathrm{~nm}$. Tubos recobertos com grafite pirolítico (Perkin Elmer, cat. No B0109322) e plataformas de L'vov (Perkin Elmer, cat. № B0109324) e tubos com plataformas integradas (Perkin Elmer, cat. № B3001264) foram usados em todos os experimentos. A plataforma de L'vov se constitui numa pequena lâmina de grafite sólido pirolítico, com uma leve depressão no centro, presa por ranhuras na parede do tubo, que atuam como trilhos, possibilitando um maior contato entre a plataforma e a parede. Já o tubo com plataforma integrada é fabricado a partir de uma única peça de grafite totalmente pirolítico, com uma plataforma de formato semicircular e menor massa, esculpida dentro do próprio tubo e presa à parede em um único ponto. Todas as leituras foram realizadas em área de pico (absorvância integrada) e o uso de rampa zero e interrupção do fluxo de argônio na etapa de atomização, precedida de uma etapa de resfriamento, completaram a obediência às condições $\mathrm{STPF}^{16,17}$. Embora o uso de modificador químico faça parte destas condições, a busca por uma análise rápida e a presença de baixas atenuações pelo fundo incentivaram o estudo da metodologia sem a presença do modificador. Neste experimento, o programa de temperatura utilizado para a determinação de chumbo na zidovudina pode ser encontrado na Tabela 1.

A variação espacial da temperatura é menor quando o tubo de grafite, na etapa de atomização, é aquecido a partir da temperatura

Tabela 1. Programa de temperatura para determinação de chumbo

\begin{tabular}{cccccc}
\hline Etapa & $\begin{array}{c}\text { Temperatura } \\
\left({ }^{\circ} \mathrm{C}\right)\end{array}$ & $\begin{array}{c}\text { Rampa } \\
(\mathrm{s})\end{array}$ & $\begin{array}{c}\text { "Hold" } \\
(\mathrm{s})\end{array}$ & $\begin{array}{c}\text { Fluxo de } \\
\text { Argônio } \\
\left(\mathrm{mL} \mathrm{min}^{-1}\right)\end{array}$ & \\
\hline 1 & 90 & 1 & 10 & 300 & $*$ \\
2 & 120 & 20 & 20 & 300 & \\
3 & 700 & 10 & 20 & 300 & \\
4 & 20 & 1 & 10 & 300 & $* *$ \\
5 & 1500 & 0 & 5 & 0 & $*$ \\
6 & 2600 & 1 & 3 & 300 & \\
7 & 20 & 1 & 5 & 300 & \\
\hline
\end{tabular}

* Amostra $(20 \mu \mathrm{L}) ; * *$ Leitura ambiente $\left(20^{\circ} \mathrm{C}\right)$ com rampa zero ${ }^{16}$. Deste modo, o analito vaporizado encontra condições mais isotérmicas para a atomização. Este estágio evita ainda a evolução de fundo durante a tomada da linha de base ("BOC error"). Por isso, o programa de temperatura possui uma etapa de resfriamento antes da atomização, embora haja dúvidas quanto à sua eficiência ${ }^{17}$.

As temperaturas de pirólise e de atomização apresentadas na Tabela 1 referem-se ao padrão de 1000 pg e foram levantadas a partir de curvas de pirólise e atomização, conforme descrito adiante.

\section{Lavagem do material}

Toda a vidraria e utensílios plásticos utilizados ficaram imersos em uma solução de Extran (Merck) a 5\% (v/v), por um período mínimo de 24 h. Após este tempo, o material era enxaguado com água corrente em abundância e, em seguida, imerso em uma solução de ácido nítrico a $10 \%$ (v/v) para a descontaminação por, pelo menos, 48 h. Após ser enxaguado várias vezes com água deionizada, o material era seco em estufa, a $30{ }^{\circ} \mathrm{C}$.

\section{Reagentes e soluções}

Todos os reagentes utilizados foram, pelo menos, de grau analítico (P.A.). A solução estoque de $1000 \mu \mathrm{g} \mathrm{mL}^{-1}$ de chumbo foi preparada a partir do concentrado Titrisol-Merck. As soluções analíticas de chumbo eram preparadas diariamente por diluições adequadas da solução estoque, em ácido nítrico 0,2\% (v/v), também Merck, tendo sido a água de diluição previamente purificada pelo sistema Milli-Q, da Millipore.

\section{Coleta}

As matérias primas são armazenadas no almoxarifado, local de coleta das amostras, em barricas que, dependendo do fabricante, são de material plástico ou fibra de vidro. Estas bombonas possuem, em média, $60 \mathrm{~cm}$ de altura e $30 \mathrm{~cm}$ de diâmetro. A amostragem é realizada com o auxílio de uma flauta pontiaguda, peça de aço inoxidável com aproximadamente $90 \mathrm{~cm}$ de comprimento e seis orifícios ( $7 \mathrm{~cm}$ de diâmetro cada e distanciados $1 \mathrm{~cm}$ entre si), por onde entram, em torno de, $145 \mathrm{~g}$ da matéria prima. Assim, para cada barrica, é preparado um "pool", com alíquotas de zidovudina coletadas em seis diferentes pontos. Deste total, $2 \%$ são analisados.

\section{Preparação das amostras}

Uma massa de 0,4 g deste "pool" de amostra foi solubilizada em $25 \mathrm{~mL}$ de ácido nítrico 0,2\% (v/v) e, posteriormente, lida sem diluição $(20 \mathrm{~mL})$.

Na ausência de materiais certificados, a acuracidade foi testada através do estudo de recuperação de uma amostra de ziduvudina enriquecida com chumbo. Cinco alíquotas de um mesmo lote da matéria prima, com uma massa média de $0,4006 \mathrm{~g}$ e desvio padrão igual a 0,0003 , foram solubilizadas. Um volume adequado de amostra, em triplicata, foi retirado de cada uma destas, e adicionados $100 \mu \mathrm{L}$ de três diferentes concentrações de chumbo de modo que se obtivessem 2,4; 10,0 e 50,0 $\mu \mathrm{g} \mathrm{L}^{-1}$ como concentrações finais do analito.

\section{RESULTADOS E DISCUSSÃO}

Os valores de absorvância integrada, contidos nas Tabelas e Figuras deste trabalho, representam a média de duas leituras, salvo no caso de disparidade entre as mesmas, quando era realizada, pelo menos, mais uma medição. Os brancos foram considerados. 


\section{Curvas de pirólise e de atomização}

As curvas de pirólise e de atomização têm por objetivo estabelecer as temperaturas ótimas de pirólise, onde ocorre decomposição da matriz sem perda do analito, e de atomização, onde o melhor compromisso entre a sensibilidade, interferências, tempo de vida do forno e tempo de atomização deve ser buscado.

Na obtenção dessas curvas, foram utilizados 1000 pg de chumbo ( $20 \mu \mathrm{L}$ de solução $50 \mu \mathrm{g} \mathrm{L} \mathrm{L}^{-1}$ de chumbo) e zidovudina enriquecida com 1000 pg de chumbo $(20 \mu \mathrm{L}$ de solução da amostra enriquecida com $50 \mu \mathrm{g} \mathrm{L}^{-1}$ de chumbo), para o programa testado.

A Figura 1 mostra as curvas de pirólise e de atomização, utilizando a plataforma de L'vov. Para 1000 pg de chumbo tanto em ácido nítrico $0,2 \%$ como na presença da zidovudina, a temperatura ótima encontrada na pirólise foi de $800{ }^{\circ} \mathrm{C}$. A temperatura de atomização que levou ao maior sinal foi $1200^{\circ} \mathrm{C}$ para o padrão aquoso. No entanto, sob estas condições, o pulso de atomização do chumbo é excessivamente largo e, por isso, é preferível o uso de uma temperatura de atomização mais elevada $\left(1500{ }^{\circ} \mathrm{C}\right)$, mesmo com alguma perda de sensibilidade.

Com a plataforma integrada, a temperatura ótima de pirólise foi de $700{ }^{\circ} \mathrm{C}$ para $1000 \mathrm{pg}$ de chumbo em ácido nítrico $0,2 \%$ e de $800^{\circ} \mathrm{C}$ na presença de zidovudina, enquanto que, com a atomização a $1400{ }^{\circ} \mathrm{C}$, obtém-se a máxima sensibilidade em ambos os casos, conforme pode ser visto na Figura 2. Neste caso, também o perfil atômico do chumbo é excessivamente largo, daí a opção por $1500^{\circ} \mathrm{C}$ como temperatura de atomização.

\section{Massas características}

As sensibilidades obtidas com a variação da temperatura de atomização, utilizando plataformas com geometrias diferentes po- dem ser encontradas na Tabela 2. Foram calculadas a partir das curvas analíticas levantadas nas condições mostradas na mesma tabela. A aplicação do teste $t$ e $95 \%$ de grau de confiança mostra que a massa característica alcançada com soluções analíticas aquosas se mantém constante com a variação da temperatura de atomização no intervalo de temperaturas estudadas e geometria da plataforma, apesar de uma pior precisão ser obtida com a plataforma integrada, em alguns casos. A sensibilidade na presença da amostra se manteve invariável com elevação da temperatura de atomização, quando do uso da plataforma de L'vov. Tal comportamento não foi repetido pela plataforma integrada, onde a menor massa característica (e igual àquelas encontradas com a outra plataforma) foi alcançada a $1400{ }^{\circ} \mathrm{C}$. Observa-se, assim, que a melhor sensibilidade da curva analítica com a amostra resultou do uso da plataforma de L'vov, independente da temperatura de atomização utilizada.

\section{Razão de sensibilidades}

A Tabela 3 mostra a influência da temperatura de atomização e da geometria da plataforma na redução da interferência observada, que foi quantificada em termos da razão $\left(b_{a p} / b_{c a}\right)$ entre as médias das inclinações das curvas de adição padrão $\left(b_{a p}\right)$ e das curvas analíticas $\left(b_{c a}\right)$ obtidas em $\mathrm{HNO}_{3} 0,2 \%$. Também aqui foi aplicado o teste $t$ (95\% de grau de confiança) para comparação das razões encontradas com as diferentes plataformas e temperaturas de atomização. $\mathrm{O}$ uso da plataforma de L'vov e temperatura de atomização de $1300^{\circ} \mathrm{C}$ permitem uma análise da zidovudina praticamente isenta de interferências. Já a utilização da plataforma integrada, assim como o aumento da temperatura de atomização não resultou em redução da interferência.

A interferência não-espectral não existe se as inclinações entre as curvas em meio aquoso e na amostra forem estatisticamente se-

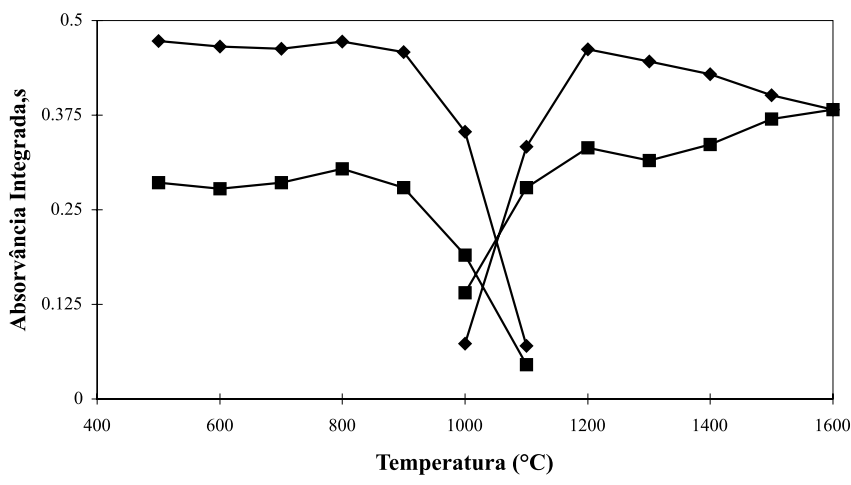

Figura 1. Curvas de pirólise e de atomização para 1000 pg de chumbo em $\mathrm{HNO}_{3} 0,2 \%(\mathrm{v} / \mathrm{v})(1000 \mathrm{pg})$ e para zidovudina $($ AZT $)$ enriquecida com $1000 \mathrm{pg}$ de chumbo $(-\mathrm{AZT}+1000 \mathrm{pg})$. Plataforma de L'vov, Tp $=700$ ${ }^{\circ} \mathrm{C}-\mathrm{Ta}=1300{ }^{\circ} \mathrm{C}$

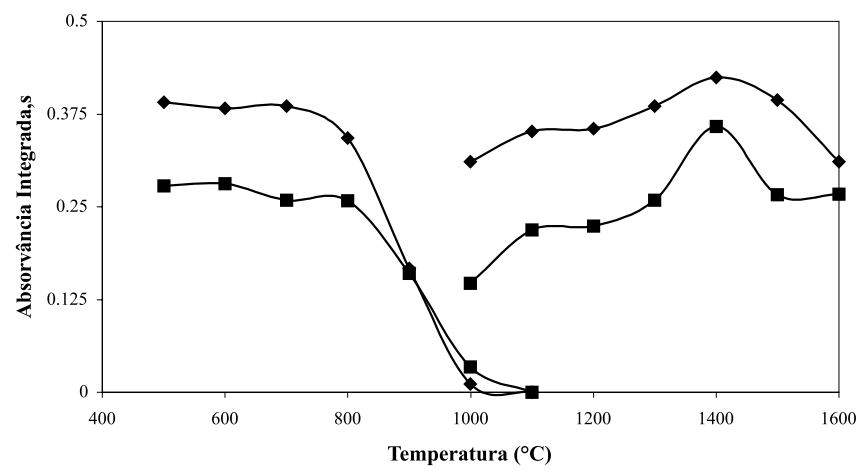

Figura 2. Curvas de pirólise e de atomização para $1000 \mathrm{pg}$ de chumbo em $\mathrm{HNO}_{3} 0,2 \%(\mathrm{v} / \mathrm{v})(1000 \mathrm{pg})$ e para zidovudina $($ AZT) enriquecida com 1000 pg de chumbo $(-\mathbf{A Z T}+1000 \mathrm{pg})$. Plataforma Integrada, $\mathrm{Tp}=$ $700{ }^{\circ} \mathrm{C}-\mathrm{Ta}=1300{ }^{\circ} \mathrm{C}$

Tabela 2. Massa característica ( $p g$ ) para $\mathrm{Pb}$ em zidovudina, usando as plataformas de L'vov e integrada

\begin{tabular}{|c|c|c|c|c|}
\hline \multirow{3}{*}{$\begin{array}{c}\text { Temperatura }\left({ }^{\circ} \mathrm{C}\right) \\
(\text { tempo de integração }=5 \mathrm{~s})\end{array}$} & \multicolumn{4}{|c|}{ Massa Característica $(p g)$} \\
\hline & \multicolumn{2}{|c|}{ Plataforma de L'vov } & \multicolumn{2}{|c|}{ Plataforma Integrada } \\
\hline & Aquoso & Matriz da Amostra & Aquoso & Matriz da Amostra \\
\hline 1300 & $10,5 \pm 0,1$ & $12,1 \pm 1,2$ & $11,6 \pm 1,5$ & $17,2 \pm 1,6$ \\
\hline 1400 & $10,2 \pm 0,7$ & $13,8 \pm 0,8$ & $10,6 \pm 0,2$ & $13,0 \pm 0,3$ \\
\hline 1500 & $10,8 \pm 0,2$ & $12,4 \pm 0,4$ & $11,4 \pm 1,4$ & $16,4 \pm 0,6$ \\
\hline
\end{tabular}

$\mathrm{Tp}=700^{\circ} \mathrm{C} ;$ volume $($ amostra $)=20 \mu \mathrm{l}$.

Os resultados obtidos são as médias de 5 replicatas das respectivas curvas analíticas e seus desvios padrão. 
Tabela 3. Razão de sensibilidades (inclinação da curva na amostra $b_{a p}$ / inclinação da curva aquosa $b_{c a}$ ) para $\mathrm{Pb}$ em zidovudina, usando as plataformas de L'vov e integrada

\begin{tabular}{ccc}
\hline $\begin{array}{c}\text { Temperatura }\left({ }^{\circ} \mathrm{C}\right) \\
\text { tempo de integração }=5 \mathrm{~s})\end{array}$ & \multicolumn{2}{c}{ Geometria da Plataforma } \\
L'vov & Integrada \\
\hline 1300 & $0,89 \pm 0,07$ & $0,74 \pm 0,06$ \\
1400 & $0,71 \pm 0,04$ & $0,82 \pm 0,04$ \\
1500 & $0,81 \pm 0,02$ & $0,79 \pm 0,03$ \\
\hline
\end{tabular}

$\mathrm{Tp}=700^{\circ} \mathrm{C}$; volume $($ amostra $)=20 \mu \mathrm{l}$.

Os resultados obtidos são as médias de 5 replicatas das respectivas curvas analíticas e seus desvios padrão.

melhantes. Porém, a técnica de adição padrão não elimina as interferências dependentes da concentração e nem as espectrais ${ }^{18}$. Assim, razão de sensibilidades diferente da unidade significa a existência de interferências. Uma vez que o corretor Zeeman, de alta capacidade e eficiência, foi utilizado, dificilmente a absorção de fundo, principal interferência espectral, será a causa desta interferência. No entanto, a menor sensibilidade da curva de adição padrão poderia ser explicada pela condensação ou por perdas na pirólise, já que um menor número de átomos do analito na forma de vapor é encontrado no volume de absorção.

As interferências na fase vapor estão relacionadas com a não isotermicidade do forno de grafite e ocorrem freqüentemente naqueles aquecidos longitudinalmente, devido ao analito volatilizar antes que o tubo de grafite ou o gás inerte tenham alcançado a temperatura final. Uma vez que não existe o equilíbrio térmico em tais fornos e a fase gasosa está mais fria do que a superfície do tubo, uma forte recombinação dos átomos do analito com os concomitantes pode ser observada. Isto leva a uma supressão substancial do sinal ${ }^{17}$.

Um fator muito importante para a eliminação deste tipo de interferência é o equilíbrio térmico do forno, onde a plataforma tem um papel significativo. Entretanto, só o uso da plataforma não cria as condições isotérmicas ideais, sendo também decisivas as outras condições do conceito STPF para reduzir ou eliminar este proble$\mathrm{ma}^{17,18}$.

\section{Acuracidade}

$\mathrm{Na}$ ausência de material de referência certificado, a acuracidade do método foi verificada pela análise de amostras de AZT, com a concentração do analito em questão abaixo do seu limite de detecção, cujas soluções foram enriquecidas com concentrações conhecidas de chumbo. Os resultados são mostrados na Tabela 4, onde, de acordo com o teste $t$ de Student e $95 \%$ de grau de confiança, não existe diferença significativa entre os valores experimentais e de referência, quando se utiliza a plataforma de L'vov e curva analítica na própria matriz. O uso da plataforma integrada só apresentou resultados concordantes com o valor de referência, no caso do AZT enriquecido com menor concentração de chumbo $\left(2,4 \mu \mathrm{g} \mathrm{\textrm {L } ^ { - 1 } )}\right.$ e curva analítica na amostra.

O propósito da plataforma é atrasar a atomização do analito, para que este seja volatilizado num ambiente completamente isotérmico e que perdas devido à condensação prematura sejam evitadas. Um tubo aquecido transversalmente com plataforma integrada oferece virtualmente condições ótimas para atomização isotérmica. Com os atomizadores do tipo Massmann, há um perfil marcante de temperatura ao longo de seu comprimento e os componentes da amostra (analito e concomitantes) podem condensar nas extremidades mais frias ${ }^{17}$.

Como a plataforma integrada foi projetada para levar mais tempo para atingir a temperatura máxima, atrasando ainda mais a atomização, pode ser que a razão do pior desempenho esteja no fato de que a massa principal da amostra seja volatilizada num ponto do tempo no qual as extremidades do tubo já estão se resfriando, de modo que uma maior condensação não pode ser efetivamente evitada. Embora esta seja uma característica do aquecimento longitudinal, seu efeito deve ser mais pronunciado com a plataforma integrada. Deste modo, mesmo fazendo uso da solução da amostra para calibração, os resultados foram inacurados, pois, à medida que a concentração do elemento aumenta, o número de átomos condensados do analito no volume de absorção também aumenta, diminuindo a sensibilidade, levando a menores inclinações da curva de adição padrão e, conseqüentemente, a resultados maiores do que os valores de referência.

\section{Limite de detecção}

O limite de detecção $(3 \sigma, n=10)$, calculado para a determinação de chumbo em zidovudina, foi obtido a partir das leituras de uma amostra isenta de chumbo, na temperatura de atomização de $1500^{\circ} \mathrm{C}$. $\mathrm{O}$ valor encontrado foi de $0,03 \mu \mathrm{g} \mathrm{g}^{-1}$ para o AZT não diluído, utilizando a plataforma de L'vov, enquanto que o uso da plataforma integrada levou a um limite de detecção $67 \%$ maior $\left(0,05 \mu \mathrm{g} \mathrm{g}^{-1}\right)$, o que já era esperado devido às maiores massas características alcançadas. Estes resultados são bem inferiores ao limite máximo permitido de chumbo na zidovudina, pela United States Pharmacopoeia (USP), que é de $10 \mu \mathrm{g} \mathrm{g}^{-1}$.

Com a aplicação do presente procedimento (plataforma de L'vov, temperatura de atomização de $1500^{\circ} \mathrm{C}$ ), os teores de $\mathrm{Pb}$ normalmente encontrados nas amostras de AZT, de diferentes procedências, variam desde menores ou iguais ao limite de detecção até $0,6 \mu \mathrm{g} \mathrm{g}^{-1}$. Como o comprimido de zidovudina, um dos componentes do coquetel da AIDS, é composto por 55,6\% de AZT, a concentração de chumbo no coquetel pode alcançar $0,33 \mu \mathrm{g} \mathrm{g}^{-1}$, o que ainda está abaixo do limite máximo permitido pela farmacopéia. Entretanto, deve-se olhar este quadro com cautela, uma vez que as contribuições relativas às outras matérias primas componentes do coquetel (didanosina,

Tabela 4. Concentração de $\mathrm{Pb}$ em amostras de AZT enriquecidas com chumbo, usando-se as duas plataformas

\begin{tabular}{|c|c|c|c|c|c|}
\hline \multirow[b]{3}{*}{ Amostra } & \multicolumn{4}{|c|}{ Valores Experimentais $\left(\mu \mathrm{g} . \mathrm{L}^{-1}\right)$} & \multirow{3}{*}{$\begin{array}{c}\text { Valores Nominais } \\
\text { de Referência } \\
\left(\mu \mathrm{g} \mathrm{L}^{-1}\right)^{*}\end{array}$} \\
\hline & \multicolumn{2}{|c|}{ Plataforma de L'vov } & \multicolumn{2}{|c|}{ Plataforma Integrada } & \\
\hline & Aquoso & Amostra & Aquoso & Amostra & \\
\hline AZT 1 & $2,2 \pm 0,2(92)$ & $2,3 \pm 0,2(96)$ & $1,8 \pm 0,3(75)$ & $2,6 \pm 0,4(108)$ & 2,4 \\
\hline AZT 2 & $9,0 \pm 0,2(90)$ & $10,3 \pm 0,2(103)$ & $8,1 \pm 0,4(81)$ & $10,7 \pm 0,6(107)$ & 10,0 \\
\hline AZT 3 & $41,3 \pm 0,6(83)$ & $50,5 \pm 0,7(101)$ & $42,2 \pm 0,6(84)$ & $56,4 \pm 1,2(113)$ & 50,0 \\
\hline
\end{tabular}

*Lab.CESTEH/FIOCRUZ: AZT enriquecido com chumbo - Valores entre parênteses: \% de recuperação

$\mathrm{Tp}=700^{\circ} \mathrm{C}-\mathrm{Ta}=1500^{\circ} \mathrm{C}$; volume $($ amostra $)=20 \mu \mathrm{l}$.

Os resultados obtidos são as médias de 5 replicatas com os respectivos desvios padrão 
estavudina, lamivudina, celulose, estearato de magnésio, talco, etc) ${ }^{11}$, e o fato de que, possivelmente, o valor limite de $10 \mu \mathrm{g} \mathrm{g}^{-1}$ seja excessivo para os pacientes já debilitados pela AIDS, devem ser considerados.

\section{CONCLUSÕES}

As temperaturas ótimas de pirólise obtidas na presença e ausência da amostra, assim como as massas características dos padrões aquosos, foram aproximadamente as mesmas com as duas plataformas. Com a utilização da plataforma integrada, a temperatura ótima de atomização foi de $1400{ }^{\circ} \mathrm{C}$ obtida para o chumbo em $\mathrm{HNO}_{3} 0,2 \%$ $(\mathrm{v} / \mathrm{v})$ e na presença da zidovudina. No entanto, esta temperatura foi de $1200{ }^{\circ} \mathrm{C}$ quando se fez uso da plataforma de L'vov. Como os pulsos de absorção mostram-se excessivamente largos entre 1100$1300{ }^{\circ} \mathrm{C}$, a temperatura de atomização escolhida foi de $1500^{\circ} \mathrm{C}$, por apresentar uma melhor definição do perfil atômico, levando à melhor razão sinal/ruído.

A variação da temperatura de atomização e da geometria da plataforma não alteram a massa característica dos padrões aquosos. Já na presença da amostra e com uso da plataforma de L'vov, esta se mantém constante frente à elevação da temperatura de atomização. Uma menor massa característica, e semelhante àquela encontrada com a plataforma anterior, é obtida a $1400^{\circ} \mathrm{C}$, utilizando o tubo com plataforma integrada.

Mesmo dentro das melhores condições de sensibilidade e interferência encontradas (uso da plataforma de L'vov e $\mathrm{T}_{\mathrm{a}}=1300{ }^{\circ} \mathrm{C}$ ), não foi possível a simples utilização da curva analítica em ácido nítrico, uma vez que uma interferência significativa permanece. Deste modo, é necessário que a calibração seja realizada com o chumbo adicionado a uma amostra com teores do analito abaixo do seu limite de detecção.

Assim, o uso da plataforma integrada também não levou à eliminação das interferências observadas. Pode ser que seu melhor desempenho seja com um equipamento de aquecimento transversal, o que possibilita maior isotermicidade do tubo. O uso de um modificador químico pode ajudar a reduzir ou eliminar as interferências encontradas com o aquecimento longitudinal.

\section{AGRADECIMENTOS}

Os autores agradecem o apoio financeiro da FAPERJ na realização do projeto dentro do qual se insere este trabalho.

\section{REFERÊNCIAS}

1. Blanusa, M.; Kralj, Z.; Arch. Toxicol. 1985, 58, 115.

2. Alfrey, A.C. Em Replacement of Renal Function by Dialysis; 3 ed.; Kluwer, Rotterdam, 1989, p. 996

3. Heise, W.; Nehm, K.; L'Age, M.; Averdunk, R.; Gunther, T.; J. Clin. Chem. Clin. Biochem. 1989, 27, 515.

4. Veer, P.; Wielen, R.P.J.; Kok, F.J.; Hermus, R.J.J.; Sturmans, F.; Am. J. Epidemiol. 1990, 131, 987.

5. Xie, Y.; Chiba, M.; Shinohara, A.; Watanabe, H.; Inaba, Y.; Industrial Health 1998, 36, 234.

6. Sanín, L.H.; Cossío, T.G.; Romieu, I.; Avila, M.H.; Salud Pública Mex. 1998, 40, 359.

7. Tsalev, D.L.; Zaprianov, Z.K. Em Atomic Absorption Spectrometry in Occupational and Environmental Health Practice; 2 ed., USA: CRC Press, 1985, v. 1.

8. Agency for Toxic Substances and Disease Registry; Toxicological Profile for Lead; US Department of Health and Human Services - Public Health Service: Georgia, USA, 1999.

9. Agency for Toxic Substances and Disease Registry; Case Studies in Environmental Medicine - Lead Toxicity; US Department of Health and Human Services - Public Health Service; Georgia, USA, 1992.

10. Saryan, L.A.; Zenz, C. Em Occupational Medicine - Lead and Its Compounds; 3 ed.; USA: Mosby - Year Book, Inc., 1994, p. 506-541.

11. Moreira, F.; Relatórios FAPERJ (Pesquisador Visitante - Convênio FIOCRUZ-FAPERJ), 1994-2000.

12. Sowell, R.L.; Phillips, K.D.; Murdaugh, C.; Tavokali, A.; Clin. Nurs. Res.1999, 8, 336.

13. Skolnick, A.A.; JAMABrasil 1998, 2, 550.

14. Francke, S.; Orosz, C.G.; Hayes, K.A.; Mathes, L.E.; Antimicrob. Agents Chemother. 2000, 44, 1900.

15. Apostoli, P.; Med. Lav. 1998, 89, 3.

16. Lajunen, L.H.J. Em Spectrochemical Analysis by Atomic Absorption and Emission; UK: The Royal Society of Chemistry, 1992.

17. Welz, B; Sperling, M.; Atomic Absorption Spectrometry, 3 ed.; Germany: Wiley-VCH, 1999

18. Curtius, A., Campos, R.C.; Espectrofotometria de Absorção Atômica Aplicada a Análise de Traços, Curso CESTEH/ENSP/FIOCRUZ, 1991. 